\title{
APPLICATION OF RADAR AND OPTICAL SATELLITE IMAGERY DATA IN LANDSLIDE POTENTIAL MAPPING OF SHESHPEER SUB-CATCHMENT IN IRAN
}

\author{
A. Imanian ${ }^{1}$, M. H. Tangestani ${ }^{1}$, A. Asadi ${ }^{2}$ \\ ${ }^{1}$ Department of Earth Sciences, Faculty of Sciences, Shiraz University, Shiraz, Fars, Iran - \\ (a.imanian@shirazu.ac.ir \& tangstan@shirazu.ac.ir) \\ ${ }^{2}$ Geological and Mining Engineering and Sciences Department, Michigan Technological University, \\ Houghton, MI, USA - (aasadi@mtu.edu)
}

KEY WORDS: Landslide Mapping, Geological Remote Sensing, Geographic Information Systems, AHP Method

\begin{abstract}
:
One of the serious dangers which threatens human communities especially those who are living in mountainous areas is the occurrence of landslides. Therefore, determination of the areas with potential for landslide events is very important for avoiding establishment of residential areas or industrial facilities. The aim of this study is to provide a landslide potential map in Sheshpeer sub-catchment, Iran, using an integration of remote sensing (RS) techniques and geographical information systems (GIS). Compared with the traditional approaches, these techniques are very fast, inexpensive and trustworthy in landslide mapping. For this purpose, we collected and produced seven data layers using GIS and RS, and then Analytic Hierarchy Process (AHP) method was applied for data analysis. Our results showed that among the twelve pervious landslide events in this area, nine of them are located in the regions with very high potentiality and the others are in highly potential regions for landslides occurrence.
\end{abstract}

\section{INTRODUCTION}

As a general definition, landslide is sliding of a mass of rocks or part of the earth down a hillside or slope, which causes a lot of damages every year (Cruden and Varnes, 1996). The mountainous countries like Iran with numerous earthquake events and diverse geological and climatic conditions, has a high potential for this event (Pourghasemi et al, 2012).

There are several factors affecting the occurrence of landslides, such as: Vegetation cover (Plants' roots cause stability of high slope hillside by absorbing water) (Mulyono, 2018), Geology (Rock type is the main criterion of sensitivity to landslides), Tectonic setting (Locating on areas with high tectonic activity leads to numerous landslides) (Guzzetti, et al., 1996), Precipitation and Snowmelt (Precipitation and the water generated as a result of snowmelt, lead to landslides because of increased weight of rock and soils and decreased resistance forces) (Paolini, et al., 2005), Height and Slope (Height and slope are some of the most important factors contributing to instability of a hillside. Higher slopes result in higher instability. So, in two similar hillsides with equal slopes, the hillside with the bigger height has the higher instability potential) (Van Western, et al., 2003).

In the last decades, many different approaches have been implemented for mapping of the slope movements such as landslide inventory map, landslide activity map, landslide relative hazard map and landslide vulnerability map (Parise, 2001). A landslide inventory map represents the spatial distribution of mass movements (Hansen, 1984). Landslide activity maps are obtained by multi-temporal aerial photo interpretation, and focus on the temporal changes in the slope movements (Soeters and van Westen, 1996). Landslide relative hazard map assesses the percentage of the area of each litho- stratigraphical unit that is occupied by landslides, and ranks the units generally on this basis (Hutchinson, 1992). Landslide vulnerability map has been defined by Varnes (1984). In order to produce this map, multiple datasets regarding distribution, type, and their values have to be known and integrated for the probability of occurrence of future landslides (Parise, 2001).

In recent decades with the progress in digital image processing techniques, landslide events can be mapped so faster and more accurate than the traditional techniques (T. Qu, et al., 2019; Fiorucci, et al., 2018; Shahabi and Hashim, 2015)

The aim of this study is to produce a landslide potential guide map in carbonate areas of Sheshpeer sub-catchment in one of the southern parts of Iran. For this purpose, seven thematic maps including drainage and lineaments density, lithology, precipitation, snow loading, slope and vegetation cover using RS and GIS techniques are prepared and the Analytical Hierarchy Procedure (AHP) is employed to assign the weights in producing the final map.

\section{STUDY AREA}

The study area is Sheshpeer sub-catchment of Jarahi-Zohre catchment discharged into Persian Gulf (29 $50^{\prime} 17^{\prime \prime}$ to $30^{\circ} 27^{\prime} 58^{\prime \prime}$ North and $51^{\circ} 53^{\prime} 26^{\prime \prime}$ to $58^{\circ} 41^{\prime} 48^{\prime \prime}$ 'East). The area is located in the border of over-thrust and folded Zagros which structurally follows the over-thrust Zagros.

The altitude of the area changes from 1488 in the flat area to 3650 meters above mean sea level (amsl) in the Gar and Barmfiruz mounts. Figure 1 shows the location of the study area in Iran and Jarahi-Zohre catchment. Lithology of the catchment mostly consists of carbonate and dolomite of Asmari-Jahrom and Sarvak formations (Fig. 2). 


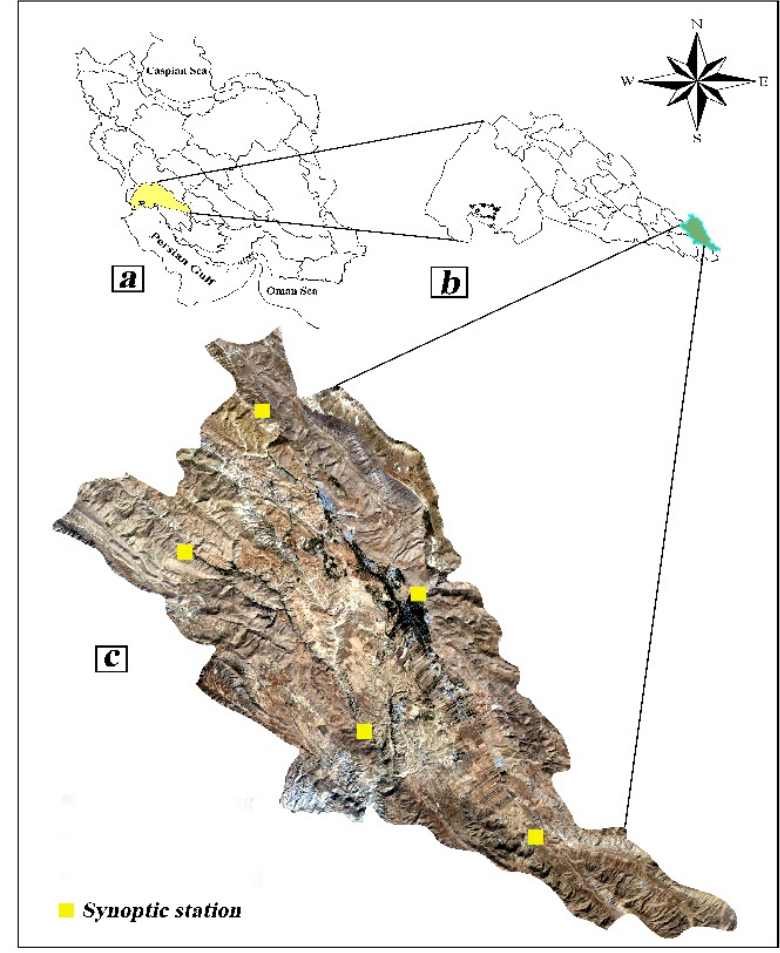

Fig. 1 a: Location of the Jarahi-Zohre catchment on the map of Iran's water basins, b: Location of Sheshpeer sub-catchment on Jarahi-Zohre divisions and c: Sheshpeer sub-catchment (RGB true color composite OLI image)

The tectonized carbonate formations have the potential for landslide due to the presence of fractures and joint systems, and there are several sinkholes in the high altitude areas of Barmfiruz mount which concentrate the surface runoff or snow melting water into the ground layer.

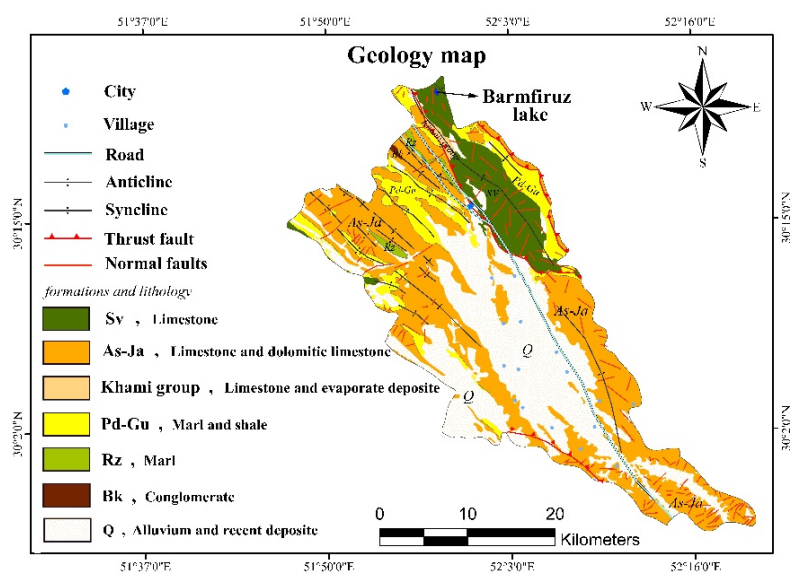

Fig. 2 Geology map of the study area (extracted from 1:100000 Ardakan, Kelestan and Dorudzan geological maps of Geological Survey of Iran)

\section{MATERIALS AND METHODS}

The data for this research are prepared as follows:

1. Primarily, as some of the data layers are obtained directly or indirectly using radar images, to prepare the raw data, these pre-processing methods were applied:

- Conversions of Digital Number (DN) data to backscatter values reflected by the surface (Amer et al., 2012)

$\circ \quad$ b) Resolving the speckle noise with a "salt and pepper" effect on raw data using "Lee" filter (Pour and Hashim, 2014)

- c) Geometric corrections of the raw data, so that the image presents geometrically as close as possible to the earth's reality.

In addition, for OLI data, these pre-processing steps were utilized:

- Converting to the radiance by the Equation 1.

$$
L_{\lambda}=M_{L} * Q_{c a l}+A_{L}
$$

Where: $\quad \mathrm{L}_{\lambda}=\operatorname{spectral}$ radiance $\left(\mathrm{W} /\left(\mathrm{m}^{2} \mathrm{sr} \mu \mathrm{m}\right)\right)$

$\mathrm{M}_{\mathrm{L}}=$ radiance multiplicative scaling factor for band

$\mathrm{Q}_{\mathrm{cal}}=$ pixels value in $\mathrm{DN}$

$\mathrm{A}_{\mathrm{L}}=$ radiance additive scaling factor for the band

- The result will be corrected to the surface reflectance using the Internal Average Relative Reflectance calibration method (IAR) to normalize the image to a scene average spectrum.

2. The satellite data from OLI sensor of Landsat 8 and C-SAR sensor of Sentinel 1 are used to prepare NDVI, DEM, slope and lineament density layers.

3. The precipitation data of five nearby meteorological stations (1980-2015) together with the prepared DEM were used to produce precipitation and snow loading potential layers.

4. Geological maps of 1:100000 (Geological Survey of Iran) and 1:25000 topographic maps (National Cartographic Centre of Iran) covering the entire study area employed for lithology and drainage density layers.

Employing the mentioned data and materials, seven informative data layers (maps) were considered as the most effective factors which were overlaid in ArcGIS software as shown in the flowchart presented in Figure 3.

The lithology layer is obtained from digitizing the Ardakan, Kelestan and Dorudzan sheets of 1:100000 geological maps. The maps were merged after geo-referencing in ENVI 5.3 software, and border of the study area was clipped.

The drainage density layer was prepared by extracted streams from 1: 25000 topographical maps using "line density" tool in ArcGIS software. The following Equation is used to calculate the density for each pixel based on Horton (1932) and Horton (1945).

$$
D_{d}=L_{t} / A
$$

Where: $\quad D_{d}=$ drainage density in $\mathrm{kg} / \mathrm{km}^{2}$

$L_{t}=$ total length of the streams

$A=$ contributing area 


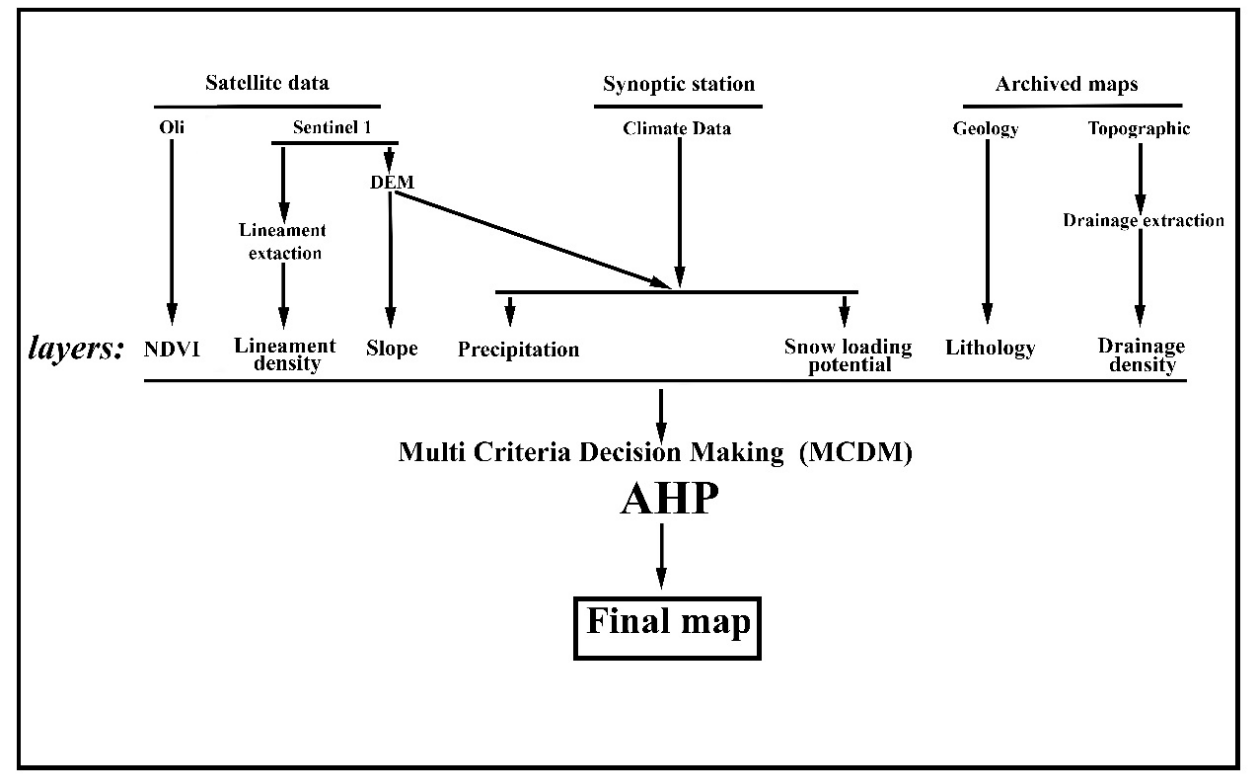

Fig. 3 Flowchart of the procedure of the study, representing the data sources and the path of the data layers preparation.

The vegetation layer was prepared by Normalized Difference Vegetation Index (NDVI) using OLI image acquired at the same times of each seasons, and averaged for four seasons of most recent four years (2014-2017) by subtracting the red reflectance values from the near-infrared, and divided by the sum of the near-infrared and red bands, as shown in equation 3 (Rouse et al., 1973).

$$
N D V I=(N I R-R E D) /(N I R+R E D)
$$

The Slope layer provided in ArcGIS 10.5 software using the DEM, extracted based on SRTM digital elevation model from the C-SAR sensor of Sentinel 1 radar satellite in SNAP software using the "Range Doppler Ortho-rectification" method.

The accuracy of this layer is checked with the 1:25000 topographic map. The produced DEM is overlaid on this map, and elevation of several pixels were compared with the contour values on the map, and a maximum difference of about 5 meters between the prepared DEM and the topographic maps is observed.

The Lineament density layer was obtained from extracted lineaments with radar data. The LINE algorithm in PCI Geomatica software was used on Sentinel 1 radar data in iw mode with two polarizations (vv and vh).

The extracted lineaments on both $\mathrm{vv}$ and vh polarization bands were merged and duplicated lineaments were removed. Finally, the generated map of lineaments was checked by Google Earth ${ }^{\circledR}$ and field survey. In this study, the lineament density layer was produced as $\mathrm{km} / \mathrm{km}^{2}$ using "line density" tool in ArcGIS software.

To prepare the precipitation layer the effect of geographical factors including altitude, latitude and longitude affecting the precipitation regime were considered (Sabziparvar et al., 2015). This layer was obtained from the relation of annual average precipitation (P) of the synoptic stations, their UTM geographical coordinates (x,y), and elevation ("h" in meters) as in equation 4.

$$
\begin{gathered}
\mathrm{P}=0.1993 \mathrm{x}+0.000084 \mathrm{y}-0.001484 \mathrm{~h}+5250.19 \\
\left(\mathrm{R}^{2}=0.88\right)
\end{gathered}
$$

To consider areas that have potential for precipitation in the form of snow, here is considered the "snow loading potential layer", the height and temperature parameters were employed in obtaining this layer.

Based on the registered synoptic data during the period of 1980 to 2015 , an elevation-temperature relationship for the absolute minimum temperature of different months of the year was obtained.

The height corresponding to zero minimum temperature was determined for each month, and the pixels having elevation higher than this elevation are considered as snow-loaded areas. Then, the twelve loaded snow maps were overlaid, and the areas with higher number of months of zero or negative temperature, were considered to have higher snow loading potential.

Several multi-criteria decision making (MCDM) techniques are proposed to combine them in GIS analysis (Joerin et al., 2001; Malczewski, 2006; Janssen et al., 2008). Analytical Hierarchy Procedure (AHP) is one of the most commonly used MCDM techniques incorporated into GIS-based suitability procedures in different fields (Marinoni, 2004; Svoray et al., 2005; Chang et al., 2008)

In AHP, selected participants rank the criteria based on pairwise comparisons to perform the AHP multi-criteria decision making process. For this study, fourteen questionnaires were distributed among the experts including faculty members of several universities and researchers who had experience in this field.

The participants were asked to rank the criteria by referring to the numerical scale of 1-9 (score of 1 for indifference between the two criteria and 9 for absolute importance) (Saaty, 2001; Ananda and Herath, 2008). 
In the first phase, the data for pairwise comparisons were analysed using ArcGIS software and AHP extension tool to obtain the final ranking for each criterion. Table 3 presents the pairwise comparisons matrix extracted from the questionnaires. The consistency of the pairwise comparisons were also checked by calculation of consistency ratio (CR) using equations 5 and 6.

\begin{tabular}{|c|c|}
\hline$C R=C I / R I(n)$ & $(5)$ \\
\hline$C I=\left(\lambda_{\max }-n\right) /(n-1)$ & $(6)$ \\
\hline
\end{tabular}

Where: $\quad C I=$ Consistency index

$R I(\mathrm{n})=$ random consistency index for matrices $n=$ Order of matrices

$\lambda_{\max }=$ Principal eigenvalue of the judgment matrix

The valid consistency has a value of CR less than 0.10 , i.e., if $(\mathrm{CR}<0.10)$, the pairwise comparison matrix has acceptable consistency and the weight values are valid to be utilized (Saaty, 2001; Saaty and vargas, 2012).

\section{RESULTS AND DISCUSSION}

Landslide phenomenon generally occurs in slopes and hillsides, and as a result of increasing tensions and decreasing strength of the rock bodies. This phenomenon, causes huge number of losses of lives and damage to assets on a yearly basis within residential areas. Therefore, providing the landslide potential map can be of great help in order to avoid such losses.

In this study, we tried to integrate the remote sensing techniques with geographic information system to generate the data layers affecting this phenomenon, and AHP method was applied to generate the final map.

Figure 4 presents the generated data layers. Table 1 presents Pairwise comparisons matrix for AHP analysis and the consistency index computed using super decision software.

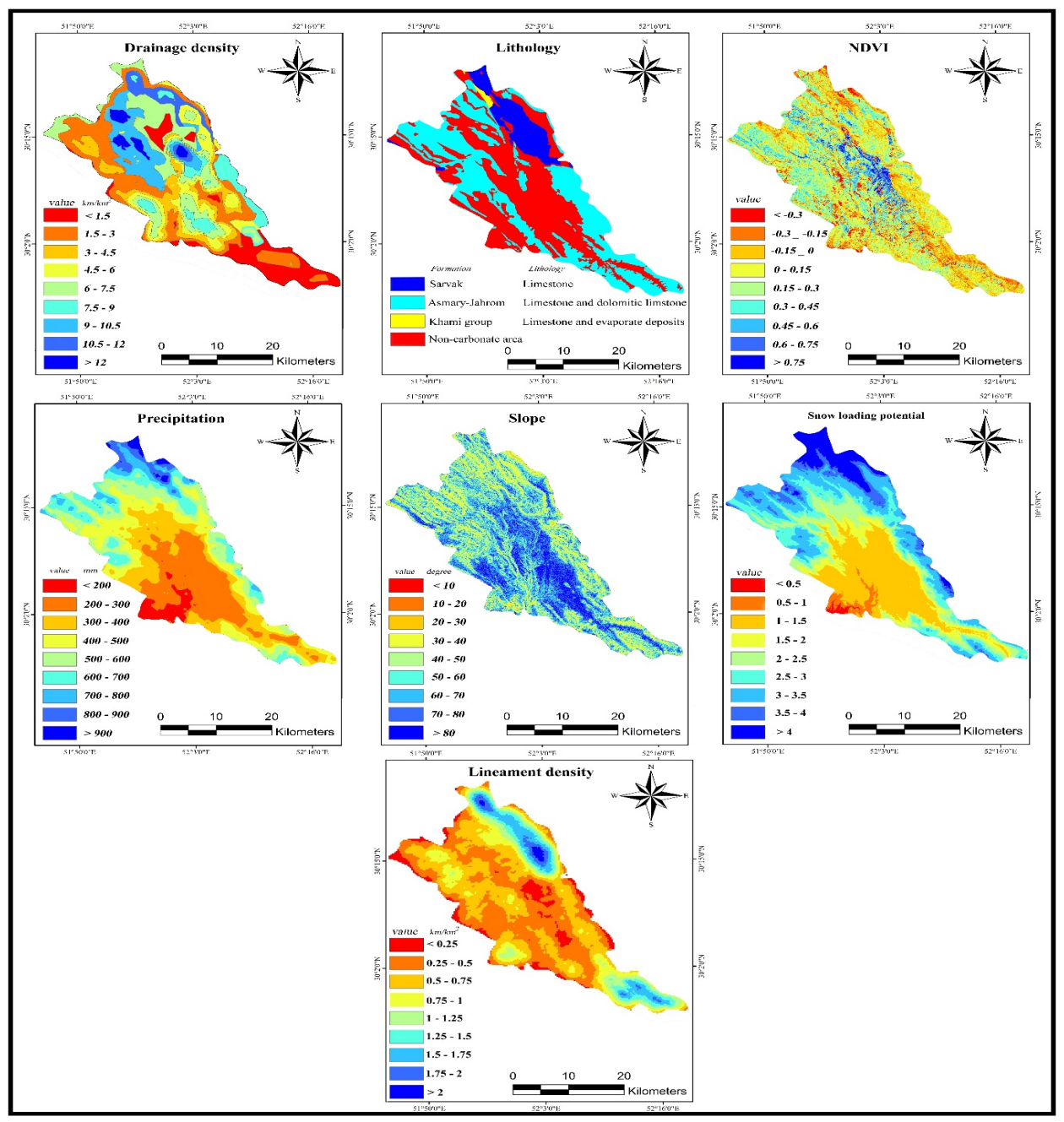

Fig. 4 generated data layers for providing landslide potential map 
Table 1: Pairwise comparisons matrix for AHP analysis and the consistency index

\begin{tabular}{|c|c|c|c|c|c|c|c|c|}
\hline criteria & Geology & Slope & Precipitation & $\begin{array}{c}\text { Vegetation } \\
\text { cover }\end{array}$ & $\begin{array}{c}\text { Drainage } \\
\text { density }\end{array}$ & $\begin{array}{c}\text { Lineament } \\
\text { density }\end{array}$ & $\begin{array}{c}\text { Snow loading } \\
\text { potential }\end{array}$ & $\begin{array}{c}\text { Final weight of } \\
\text { each criteria }\end{array}$ \\
\hline Geology & 1 & 1.2 & 3 & 6 & 4.28 & 1.5 & 10 & 0.30 \\
\hline Slope & 0.83 & 1 & 2.5 & 5 & 3.57 & 1.25 & 8.33 & 0.25 \\
\hline Precipitation & 0.33 & 0.4 & 1 & 2 & 1.42 & 0.5 & 3.33 & 0.10 \\
\hline Vegetation cover & 0.16 & 0.2 & 0.5 & 1 & 0.71 & 0.25 & 1.6 & 0.05 \\
\hline Drainage density & 0.23 & 0.28 & 0.7 & 1.4 & 1 & 0.35 & 2.33 & 0.07 \\
\hline Lineament density & 0.66 & 0.8 & 2 & 4 & 2.85 & 1 & 6.66 & 0.20 \\
\hline Snow loading potential & 0.1 & 0.12 & 0.3 & 0.6 & 0.42 & 0.15 & 1 & 0.03 \\
\hline
\end{tabular}

One of the most trusted methods in verification of such maps is to investigate the match between locations where landslides have occurred in recent years and the final generated maps. Figure 5 presents the final provided map and locations of the landslides that were occurred in the last fifteen years. Our observations show that among the six previous landslides, five of them $(83 \%)$ are located in the high and very high potential areas of the produced landslide map.

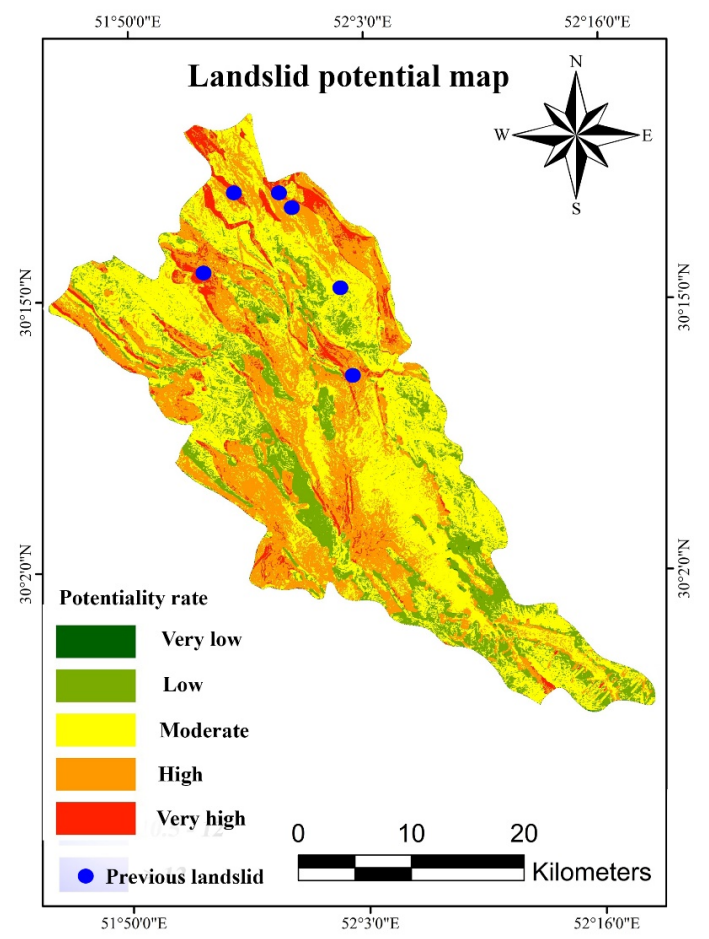

Fig.5 the final provided map and locations of the landslides that were occurred in the last fifteen years

\section{CONCLUSIONS}

Geographic Information System (GIS) and Remote Sensing (RS) applications reveal strong potential for the use in preparation of landslide potential study. The study showed that remote sensing data from radar and optical satellites offer the potential of application in producing informative data layers integrated in ArcGIS to produce the landslide potential map.
Several factors affect the slide rate of the rock bodies which result in the occurrence of landslides. However, these factors have different impact on the process. Geology including lithology and tectonic setting as endogenous factors and drainages are the key factors in occurrence of the landslides.

The climatological parameters including precipitation, snow and temperature, and morphological factors such as slope are considered as exogenous factors which are also important in occurrence of landslide phenomenon.

\section{REFERENCES}

Amer R, Kusky T, El Mezayen A (2012) Remote sensing detection of gold related alteration zones in Um Rus area, Central Eastern Desert of Egypt. Advances in Space Research, 49(1), 121-134.

Ananda J, Herath G (2008) Multi-attribute preference modelling and regional land-use planning. Ecological economics, 65(2), 325-335.

Chang NB, Parvathinathan G, Breeden JB (2008) Combining GIS with fuzzy multicriteria decision-making for landfill siting in a fast-growing urban region. Journal of Environmental Management, 87(1), 139-153.

Cruden, D. M., \& Varnes, D. J. (1996). Landslides: investigation and mitigation. Chapter 3-Landslide types and processes. Transportation research board special report, (247).

Fiorucci F., Giordan D., Santangelo M., Dutto F., Rossi M and Guzzetti F (2018). Criteria for the optimal selection of remote sensing optical images to map event landslides. Natural Hazards and Earth System Sciences, 18(1), 405-417.

Guzzetti F., Cardinali M., and Reichenbach P (1996). The influence of structural setting and lithology on landslide type and pattern. Environmental \& Engineering Geoscience, 2(4), 531-555.

Horton RE (1932) Drainage-basin characteristics. Eos, Transactions American Geophysical Union, 13(1), 350-361.

Hansen A (1984) Landslide hazard analysis. In: Brunsden, D. and Prior, D.B., (Eds.), Slope instability. John Wiley and Sons, New York, 523-602. 
Horton RE (1945) Erosional development of streams and their drainage basins; hydrophysical approach to quantitative morphology. Geological Society of America Bulletin, 56(3), 275-370.

Hutchinson, J.N., Keynote paper: landslide hazard assessment. Proc. $6^{\text {th }}$ lnt. symp. on Landslides, Christchurch, 3, 180.5- I84 I, 1992.

Janssen R, van Herwijnen M, Stewart TJ, Aerts JC (2008) Multiobjective decision support for land-use planning. Environment and Planning B: Planning and Design, 35(4), 740-756.

Joerin F, Thériault M, Musy A (2001) Using GIS and outranking multicriteria analysis for land-use suitability assessment. International Journal of Geographical information science, 15(2), 153-174.

Malczewski J (2006) Ordered weighted averaging with fuzzy quantifiers: GIS-based multicriteria evaluation for land-use suitability analysis. International Journal of Applied Earth Observation and Geoinformation, 8(4), 270-277.

Masoodian SA (2015) Geographical factors affecting variability of precipitation regime in Iran. Theoretical and Applied Climatology, 120(1-2), 367-376.

Marinoni O (2004) Implementation of the analytical hierarchy process with VBA in ArcGIS. Computers \& Geosciences, 30(6), 637-646.

Mulyono, A., Subardja, A., Ekasari, I., Lailati, M., Sudirja, R., \& Ningrum, W. (2018, February). The Hydromechanics of Vegetation for Slope Stabilization. In IOP Conference Series: Earth and Environmental Science (Vol. 118, No. 1, p. 012038). IOP Publishing.

Paolini, L., Villalba, R., \& Grau, H. R. (2005). Precipitation variability and landslide occurrence in a subtropical mountain ecosystem of NW Argentina. Dendrochronologia, 22(3), 175180.

Parise, M. (2001). Landslide mapping techniques and their use in the assessment of the landslide hazard. Physics and Chemistry of the Earth, Part C: Solar, Terrestrial \& Planetary Science, 26(9), 697-703.

Pour AB, Hashim M (2014) Structural geology mapping using PALSAR data in the Bau gold mining district, Sarawak, Malaysia. Advances in Space Research, 54(4), 644-654.

Pourghasemi, H. R., Pradhan, B., \& Gokceoglu, C. (2012). Application of fuzzy logic and analytical hierarchy process (AHP) to landslide susceptibility mapping at Haraz watershed, Iran. Natural hazards, 63(2), 965-996.

Qu, T., Xu, Q., Liu, C., Li, Z., Chen, B., \& Dai, K. (2019). Radar remote sensing applications in landslide monitoring with multi-platform inSAR observations: A case study from China. ISPRS Geospatial Week 2019.

Rouse J, Haas R, Schell J, Deering D (1973) Monitoring vegetation systems in the Great Plains with ERTS. In 3rd ERTS Symposium, NASA SP-351 I, 309-317.
Saaty, T. L., Vargas, L. G. (2012). The seven pillars of the analytic hierarchy process, Models, Methods, Concepts \& Applications of the Analytic Hierarchy Process, International series in operations research \& management science 175, 23 40 , Springer.

Sabziparvar AA, Movahedi S, Asakereh H, Maryanaji Z, Saaty, T. L. (2001). Deriving the AHP 1-9 scale from first principles. ISAHP 2001 proceedings, Bern, Switzerland.

Shahabi, H., \& Hashim, M. (2015). Landslide susceptibility mapping using GIS-based statistical models and Remote sensing data in tropical environment. Scientific reports, 5, 9899.

Soeters R., and van Westcn, C.J (1996) Slope instability recognition, analysis, and zonation. In: Turner, AK. and Schuster, R.L., (Eds.), Landslides. investigation and mitigation, Transp. Res. Board, spec. rep. 247. Nat. Acad. Press, Washington, D.C., 129-177.

Svoray T, Bar P, Bannet T (2005) Urban land-use allocation in a Mediterranean ecotone: Habitat heterogeneity model incorporated in a GIS using a multi-criteria mechanism. Landscape and Urban Planning, 72(4), 337-351.

Van Westen, C. J., Rengers, N., \& Soeters, R. (2003). Use of geomorphological information in indirect landslide susceptibility assessment. Natural hazards, 30(3), 399-419.

Vames D.J (1974) The logic of geological maps, with special reference to their interpretation and use for engineering purposes, US Geol. Survey. Prof. Paper 837,48 